\title{
Relief from a Certain Kind of Personhood in ASMR Role-Play Videos
}

\section{Emma Bennett}

\begin{abstract}
The writer Emma Bennett first heard 'ASMR' (autonomous sensory meridian response) mentioned during interdisciplinary conversations about lullabies and the politics of work and rest while at Hubbub. After Googling the practice, Emma began watching Olivia's Kissper ASMR to aid sleep and to indulge a long-held susceptibility to 'tingles'. Here, Emma asks: Could this spectatorial practice aimed at attaining a dreamy, sleepy passivity be reframed as an active research practice? And, might this counterintuitive move raise productive theoretical questions about activity and passivity, questions that open on to the ethics of rest and its opposites?
\end{abstract}

Keywords Address - Apostrophe Autonomous sensory meridian response Body $\cdot$ Performance $\cdot$ YouTube

1.

Our encounters take place in a vague but easily imagined context. A room, domestic yet anonymous. A feeling of the door being closed. Not secretive so much as legitimately, respectfully private. Perhaps there isn't even

E. Bennett $(\square)$

Queen Mary University of London, London, United Kingdom

e-mail: e.l.bennett@qmul.ac.uk

(c) The Author(s) 2016

F. Callard et al. (eds.), The Restless Compendium,

DOI 10.1007/978-3-319-45264-7_16 
a door? There wouldn't need to be one, not now I am here. In any case, I can't turn my head to look. My perception of this space is ever so slightly blurred at the edges.

Welcome, she says, you are just on time.

Smiling. Her face fills my vision. She looks into my eyes, and she looks at my eyes. She speaks to the space where my face would be. ${ }^{i}$

I can help you with your migraines, she says, but first we will have to do some examination that will include checking your face and your facial muscles.

As she says this she brings both her hands to her own face - she touches it twice, indicatively, symmetrically, with perfectly straight fingers.

So let me get started, she says. I'll just gently touch your face. Her hand comes towards me. Fingertips blur as they appear in my vision close up.

I'll just gently bring pressure on your cheeks, she says, and the area of your jaw.

Her gaze is fixed somewhere below my eyes, as her thumbs and fingers move at the outer edges of ... what? My vision? Or my face? The four corners of it - upper eyebrow, lower jaw - drawn or dabbed gently on to the space between and in front of us. It's a mime, this momentary touch, but she definitely has nice fingers.

This is Olivia: her face, her hands, in detail, close up. ${ }^{\text {ii }}$ The shadow on the inside of her right eye is violet, underneath it a little smudge of purple. I am looking at this stylish eye smudge, which is deliberate, like all her movements, and she's making something about the space between and in front of us palpable, shapely. Of course, she's an image on a screen: an inscription. And she's stroking not my face, but my computer screen from the inside. But I strongly feel the contiguity of our rooms, hers opening on to mine with this as the window - this, my screen, my face.

2.

Olivia has called this video 'CLOSE UP Medical DOCTOR Role Play'. ${ }^{1}$ This is a mutual performance. A two-sided role play. I can see her but she can't see me. She pretends to see me: This is how it works. She looks intently in my direction, and I feel that gaze, tangibly, on my face. She

\footnotetext{
${ }^{\mathrm{i}}$ Cf. Chap. 19.

ii Cf. Chap. 15.
} 
is smiling, but serious, and speaks with the calm, attentive expertise of a medical professional. But the glasses she is wearing are too big; they keep slipping down her nose. A reminder that her seriousness, although it is earnest, is not entirely serious.

It is not only her performance, it is mine, too. I have to go along with it, even just a tiny bit, for it to work. I have to receive these recorded, mediated attentions as if they were really directed at me, personally, in the here and now. And it works: when Olivia says, I'll just gently touch the area of your jaw, my jaw responds, it feels noticed. It's sort of like it blushes, flinches ticklishly at the mention of its name.

With the serious, scientific-sounding term 'autonomous sensory meridian response' (ASMR) in mind, I read that, in biology, an autonomous response 'usually refers to an involuntary motor reflex such as breathing or vomiting directed by the spinal cord that is not processed by the brain'. ${ }^{2}$ Is this an accurate way to describe what is happening when Olivia says your jaw, and my jaw tingles in response? In other words, is my jaw's response 'autonomous'? Is this something my jaw does on its own? It somehow feels that way, but cannot be, for it is the verbal cue that calls my jaw into play. Olivia's spoken words are what allow me to imagine and thus feel as if certain parts of my face are being, or about to be, touched. And, as one who thinks with and through performance, my interest lies precisely in the 'as if ...' and the creative and theoretical space it opens. For me, ASMR is less a question of biological autonomy than linguistic agency - of a body felt, a self experienced, through language. .ii $^{-}$

She pretends to see me, speak to me. I pretend she is examining me, that when she says you, she means me. And yes, when she says your jaw, I feel as if my jaw is playing along too, imagining itself to be another jaw, the one Olivia is imagining, fictionally examining. The whole thing relies on a deliberate confusion between the somatic and the linguistic, the willed and the involuntary, self and body, person and thing.

\section{3.}

Pitched somewhere between a careful ritual and a routine check-up, the 'close personal attention' explicitly offered by ASMR videos is reassuring precisely inasmuch as it is impersonal. Olivia dedicates her gestures not to a named person (this would be distractingly specific), but, repeatedly, to

iii Cf. Chap. 7. 
'you'. It is her repeated refrain, this ... for you. When she introduces into the frame a stack of cotton wool pads in a half-deflated polythene tube, uncrumpling gently, pulling out its tiny frayed drawstring, for the sound, she will say I have this cotton wool for you. ${ }^{3}$

The philosopher Adriana Cavarero calls attention to the second-person pronoun, and in so doing, subtly critiques conventional ways of understanding sociality. The 'you,' she writes, 'is a term that is not at home in modern and contemporary developments of ethics and politics. ${ }^{4}$ Individualist doctrines celebrate the 'I', collective movements the 'we'. Devoid of the fullness of self-assertion or the positive connotations of friendship, community and political solidarity, 'you' can tend to get overlooked. An empty, contentless indicator, it marks the destination of any address whatsoever. A 'you' might be imaginary or deferred. It could be anyone or no one. It designates a gap to be filled, nothing more.

Cavarero proposes a relational ethics that starts with the question: 'Who are you?' As Judith Butler notes, 'This question assumes that there is an other before us whom we do not know and cannot fully apprehend. ${ }^{5}$ Olivia's 'you' is not 'me', never quite; it just coincides with the space that I am, for this time. This is not a scary or unhappy interpellation, because not only is it explicitly provisional, it's also full of reassurance. You have a beautiful scalp, very symmetrical, very smooth, says Olivia, as she speaks into being a person-shaped space, a body devoid of the distracting specifics of 'me'.

4.

In her video called ' 1 Hour FACIAL Spa BLISS', Olivia proffers an array of little vessels and products and curiously textured items, selected for you, and for their sound. Each thing is held up between thumb and forefinger, carefully introduced, displayed, tested out, tapped and sounded out. Salt crystals, for example, tipped gently into a small bowl.

And I will be mixing this for you here, she says, in this cute little container, and I will be using this stick, tap-tap of nail on stick, for the mixing, and this one is made of bamboo.

For little articulations, attentions like this, they rely on sensitive microphones, which pick up surface-level meetings between the body and the things it touches. Finger pads, for example, ever so slightly moist, adhering momentarily to the tacky plastic of a travel-sized shampoo bottle, to make a gentle thuck-thuck. This miniaturization of attention is both pedantic and luxurious: a feeling of glazed pleasure, a passive sort of enchantment. 
Videos like this are recorded using 'binaural' equipment: two microphones shaped like human ears, and spaced accordingly, in order to capture sound in three dimensions. When I listen, with in-ear noise-cancelling speakers, it's as if I insert my head into that space, the space Olivia describes with her words and gestures. Where the video camera is concerned, there is not quite such a snug fit between my own sensing apparatus and the recording equipment. At the scene of recording, there is an eye-like lens; at the scene of spectating, a screen. This is the window through which I look, and on to which Olivia projects my entire face.

Amongst the unresolved issues of the ASMR role-play video, particularly of the face-touching variety: Where is my nose? Does it float transparently in the middle of my face/screen? Or should it be located somewhere unseen, off the lower edge, below my line of sight? Different ASMR artists have devised their own ways around this predicament. Olivia will say and now I'm just going to do your nose, and at the same time stroke, say, a cotton wool pad (freshly moistened in splashy, ceremonious fashion, with fragrant rose water) in a vertical line down the middle of the screen. $A h$, some part of me thinks, that's surely not where my nose is, would be, should be; surely that's the middle of my ... eye?

Tricky moments such as this do not, for me, ruin the effect of the role play. I find the mediated encounter intensely lovely not in spite of these wonky conceits, but because of them. The representational conventions of the ASMR role-play are not quite established, still buzzing around the edges, and I like those moments when the joins are visible because they intensify the intimacy, the sense of colluding in a fiction.

\section{5.}

When I am watching Olivia, I am participating in the fiction, the role-play. (Although it doesn't look much like 'participation', what I am doing here, horizontal and limp-limbed, staring into a screen.) Of course, I am aware, as she knows I am, that she is, in fact, speaking not to 'me' (or anybody's body or face) but to a camera and a microphone. Her performance of care, tending the body and its parts, is directed towards this hardware, these devices.

In poetry or rhetoric, the direct address of an absent, or indeed an inanimate, being is named 'apostrophe'. As when Yeats, for example, intones 'O chestnut tree', or Shelley 'O wild West Wind'. The term 'apostrophe' is, according to Barbara Johnson, 'based etymologically on the notion of turning aside, of digressing from straight speech', and 'manipulates the I/ thou structure of direct address in an indirect, fictionalised way'. She calls 
it 'a form of ventriloquism' whereby the speaker throws not only their voice, but also human form into the addressee, 'turning its silence into mute responsiveness' ${ }^{6}$

Olivia's spoken performance is directed - intently, exaggeratedly towards me, the mutely responsive viewer. But, in her room, my proxy is a technological assemblage, a camera plus binaural microphone. And so there is something simultaneously voyeuristic and thingified about this position. I am looking out from the position of the thing Olivia once addressed as though it were a person, a human being with a face. Here a curious doubling takes place: a thing is being addressed as if it were a person, and via the mediation of a screen, a digital interface, a person (me) can experience this address from the position of the thing. This might explain what I feel to be an odd displacement of my personhood, I am being addressed as if I were a person, but my position, my viewpoint, is that of a thing.

6.

Why is this so nice, the feeling of this uncertain status between personhood and objecthood? Could it be that it offers a relief from a certain kind of personhood? Projecting oneself outwards into space, into social space, can be exhausting, perhaps increasingly so in the performance-driven economy of late capitalism, where the kind of work to which we are encouraged to aspire is not that which produces material goods, but that which delivers services and creates and maintains social networks. ${ }^{7}$ iv Against this backdrop, it might well be that the embodied social acts of projecting one's 'self' out towards others - smiling, speaking, comporting one's body in relation to others, turning one's face to the world - feel increasingly like work.

Is this what, for me, makes the address of the ASMR role play restful, relieving, over and above those real-life caring encounters it imitates?v At the doctor, the spa, I may be granted a degree of anonymity (these professional carers do not know me), but I am still taxed with the effort of acting like a person, projecting some coherent image of myself. But here, with Olivia, who promises me, amongst other things, a peel-off mask, a loose personhood is projected on to me by someone who cannot even see my face. This intervenes in the projecting of a coherent, bounded, personness outwards into the world; here is someone projecting a neutral and impersonal personhood (as in, human shape, human form) on to me.

iv Cf. Chaps. 8, 14, 20 and 22.

${ }^{v}$ Cf. Chap. 9. 
When Olivia says, you bave a beautiful scalp, very symmetrical, very smooth, and somewhere off-screen, her fingers find my hairline with a dry grassy sound which reminds me my skull is there, and also not there, I am her 'you', spoken into place. I hover between states. My body is imaginary (to Olivia) and irreducibly here (in my room, on my bed). I'm doubled, folded over and pleasantly displaced. This is how it feels, I think, to feel (and luxuriate in) what it is to be $a$ 'you'. No 'you' in particular, this given you, the one that happens to be the object - the much-prized object - of this occasion of address.

\section{Notes}

1. Olivia's Kissper ASMR, 'CLOSE UP Medical DOCTOR Role Play: Binaural ASMR EXAMINATION with CRANIOSACRAL THERAPY for Migraines', 11 February 2015, https://www.youtube.com/watch?v=Nyz0TRPWEag.

2. Quoted in Joceline Andersen, 'Now You've Got the Shiveries: Affect, Intimacy, and the ASMR Whisper Community', Television of New Media 16, no. 8 (2015), 687; see also Chap. 15 of this volume.

3. Olivia's Kissper ASMR, 'I Hour FACIAL Spa BLISS: Binaural ASMR Role Play with Sugar Scrub \& Relaxation Music', 12 June 2015, https:// www.youtube.com/watch?v=Viy8TRtAWQw.

4. Adriana Cavarero, Relating Narratives: Storytelling and Selfhood (London and New York: Routledge, 2000), 90.

5. Judith Butler, Giving an Account of Oneself (New York, N.Y.: Fordham University Press, 2005), 31.

6. Barbara Johnson, 'Apostrophe, Animation, and Abortion', in The Barbara Johnson Reader: The Surprise of Otherness, ed. Melissa Fenerstein, Bill Johnson González, Lili Porten and Keja Valens (Durham, N.C.: Duke University Press, 2014), 218.

7. For more on this, see Michael Hardt, 'Affective Labor', Boundary 226 , no. 2 (1999): 89-100.

Emma Bennett performs, writes and makes recordings - working with language, voice, sound and objects. She is interested in figures of speech, obstacles and involuntary acts. She has recently performed at Santozeum Museum (Santorini, Greece), FIAC (Paris) and Wellcome Collection (London). 
(c) (1) This chapter is distributed under the terms of the Creative Commons BY Attribution 4.0 International License (http://creativecommons.org/ licenses/by/4.0/), which permits use, duplication, adaptation, distribution and reproduction in any medium or format, as long as you give appropriate credit to the original author(s) and the source, a link is provided to the Creative Commons license and any changes made are indicated.

The images or other third party material in this chapter are included in the work's Creative Commons license, unless indicated otherwise in the credit line; if such material is not included in the work's Creative Commons license and the respective action is not permitted by statutory regulation, users will need to obtain permission from the license holder to duplicate, adapt or reproduce the material. 